\title{
EL PACTO DE PERMANENCIA EN LA RELACIÓN LABORAL. COMENTARIO A LA SENTENCIA DE LA CORTE SUPREMA DE 21 DE AGOSTO DE 2007, ROL 5581-2005, "UNIVERSIDAD DE CONCEPCIÓN CON OLMOS COELHO”*
}

\author{
Alfredo Sierra Herrero** \\ Universidad de Los Andes
}

\section{ANTECEDENTES DEL CASO}

\subsection{Resumen De LA CUESTIÓN}

El caso trata de un profesor asistente (en adelante "el trabajador") de la Facultad de Medicina de la Universidad de Concepción, quien decide iniciar unos estudios de perfeccionamiento en Estados Unidos. Por tal motivo, se celebra un convenio en virtud del cual la Universidad le concedía al profesor un permiso con goce de remuneraciones por concepto de beca de estudios, y éste se obligaba a regresar a la Universidad al término del permiso o de las prórrogas, en el cargo y jornada que desempeñaba, por un plazo no inferior al de duración del permiso más un año, con máximo de cinco.

La cláusula tercera de dicho convenio señalaba que en caso que el trabajador no cumpliera con las obligaciones indicadas, quedaba obligado a restituir a la Universidad la totalidad de los fondos o sumas de dineros que ésta le hubiere pagado durante el período que efectivamente hizo uso del permiso remunerado ${ }^{1}$. Asimismo en la cláusula sexta del convenio, las partes acordaron que si el contrato terminaba por causa legal que implicaba culpa del trabajador, se entendía que quedaba obligado a la restitución de los fondos o dineros de la misma manera como se expresó anteriormente. Además, para garantizar el cumplimiento de todas las obligaciones contraídas por el trabajador, se estipuló, en la cláusula octava del convenio, que éste debía contratar por cuenta de la Universidad de Concepción, un seguro de fidelidad funcionaria ante la compañía aseguradora que la Universidad determinara.

El trabajador fue despedido por la Universidad, poniéndole término al contrato de trabajo por ausencia injustificada a sus labores e incumplimiento grave de las obligaciones que imponía al contrato. Como consecuencia de lo anterior, la Universidad cobra el seguro antes indicado, pero éste cubre sólo una parte del total de las cantidades adeudadas. Por este motivo, la Universidad demanda al trabajador exigiendo la totalidad de los fondos o sumas de dineros que le había pagado durante el

\footnotetext{
* La redacción de este comentario ha contado con la ayuda del Fondo Nacional de Ciencia y Tecnología de la República de Chile, en el marco del Proyecto Fondecyt Regular $\mathrm{N}^{\circ} 1130664$, titulado "Régimen laboral de gerentes y personal directivo de exclusiva confianza”, en el cual el autor es investigador responsable.

** Licenciado en Ciencias Jurídicas y Sociales, Universidad de Chile. Abogado. Doctor en Derecho, Universidad de Santiago de Compostela. Profesor de Derecho del Trabajo, Universidad de Los Andes (Chile). Correo electrónico: asierra@uandes.cl

La redacción de este comentario ha contado con la ayuda del Fondo Nacional de Ciencia y Tecnología de la República de Chile, en el marco del Proyecto Fondecyt Regular $N^{\circ} 1130664$, titulado "Régimen laboral de gerentes y personal directivo de exclusiva confianza”, en el cual el autor es investigador responsable.
} 
Alfredo Sierra Herrero / El pacto de permanencia en la relación laboral.

período que hizo uso del permiso remunerado. Por su parte, el demandado sostiene que a la Universidad sólo le corresponde recibir lo que ha cobrado del seguro.

\subsection{Decisión de La Corte}

\subsubsection{Totalidad de los desembolsos}

Como primera cuestión, es necesario señalar que como el demandado no reclamó del despido, se entiende como un hecho establecido que éste incurrió en la causal de despido invocada por la Universidad ${ }^{1}$.

Bajo este supuesto, el Corte Suprema considera que el profesor debe responder a la Universidad por la totalidad de los desembolsos que ésta le ha efectuado. Se señala así que la:

"Circunstancia de haber contratado la referida póliza no limita la responsabilidad del demandado frente a lo que era su deber de reparar los perjuicios que su conducta culpable había ocasionado, cuestión que, por lo demás, se corresponde con el espíritu de la obligación de indemnizar en términos totales a la empleadora de que da cuenta el convenio, y se encuentra acorde con la naturaleza misma de la institución de la indemnización de perjuicios, que exige, en los términos que se ha pactado en el convenio de autos, reponer las cosas al estado en que ellas se encontraban antes del acto que motivó la disposición patrimonial por parte de la Universidad".

\subsubsection{Naturaleza del convenio: competencia procesal}

La primera cuestión que es resuelta por la Corte Suprema en este caso, es un asunto de competencia, en particular si el convenio de permanencia es de naturaleza civil o laboral ${ }^{2}$. Lo anterior, porque la demanda de la Universidad se había presentado en sede civil, y el profesor demandado interpone una excepción dilatoria al entender que la jurisdicción llamada a conocer era la laboral.

A este respecto, la Corte Suprema resuelve que dicho convenio tiene carácter civil, y por tanto el tribunal ordinario puede conocer de la acción interpuesta. En este sentido afirma que:

“Tanto del reglamento del becario como del convenio de permanencia surge un vínculo civil, distinto del laboral, pues en esencia ambos imponen al becario la obligación de retornar a su puesto de trabajo y desempeñarse en él por cierto período o, en su defecto, devolver las sumas pagadas por la universidad durante el período correspondiente. Estas obligaciones no son propias de un contrato de trabajo individual, en la medida en que ellas no se refieren a la prestación de servicios, sino al pago de indemnizaciones o multas, como obligación alternativa a la de permanencia en sus labores, lo que resulta ajeno a una relación laboral”"

\footnotetext{
Véase considerando $4^{\circ}$ de la sentencia de la Corte de Concepción, 29 de agosto de 2005, Rol 2991-2001.

Corte Suprema 31 de marzo de 1999, Rol 591-98.

Corte Suprema 31 de marzo de 1999, Rol 591-98.
} 


\subsubsection{Justificación de esta clase de convenio}

La Corte Suprema dedica algunos párrafos para justificar la existencia de esta clase de pactos. Así entiende que su fundamento se encuentra en un interés recíproco de las partes. Por un lado, para la Universidad dicho interés consiste en:

"Proporcionar las herramientas idóneas para una adecuada capacitación de su personal docente, otorgando los medios económicos que estaban a su alcance, a cambio de la declaración de voluntad del académico en orden a restituir el señalado esfuerzo de la casa de estudios, a través del trabajo desarrollado por aquél durante un determinado tiempo, con el cual se entendería pagada la beca otorgada”.

Por otro lado, para el profesor el beneficio se encuentra en "obtener en forma segura y periódi$\mathrm{ca}$, ingresos que le permitirían financiar estudios de perfeccionamiento en condiciones de excelencia académica, a cambio de la obligación de retornar a ejercer sus funciones a la misma casa de estudios que lo becó".

En síntesis, se señala que "queda claro que la causa de la carga asumida por una la Universidad y su interés por contar con personal calificado representa la génesis de la obligación del docente, al que se le impone la permanencia al servicio de la Universidad, a cambio de la beca obtenida”.

\section{COMENTARIO DE LA SENTENCIA}

\subsection{Noción Y FUndamentos DEL CONVENIO DE PERMANENCIA}

La figura en análisis se conoce como pacto o convenio de permanencia en la empresa, que puede ser definido como el acuerdo por el cual un "trabajador se compromete a permanecer en la misma empresa durante un tiempo determinado"4; luego si éste desea abandonar la empresa, el pacto lo único que provocará es la obligación de resarcir los perjuicios ocasionados al empleador 5 . SiRvent señala que el presupuesto sobre el que descansa la validez jurídica de estos pactos se encuentra en la especialización profesional del trabajador ${ }^{6}$. De esta especialización resultaran beneficiadas ambas partes del contrato de trabajo. Por un lado, la empresa contará con dependientes dotados de un perfil profesional adecuado para responder a las demandas del mercado, pudiendo alcanzar así la mayor competitividad posible ${ }^{7}$. Por otra parte, el trabajador enriquecerá su patrimonio personal y profesional y, por ende, pasará a ser valorado en el mercado ${ }^{8}$.

Nuestra legislación laboral no regula esta clase de pactos, sin embargo en el ámbito de la administración pública se trata específico este aspecto. En particular, el art. 31 del Estatuto Administrativo (ley $\mathrm{N}^{\circ} 18.834$ ) que dispone lo siguiente:

\footnotetext{
Irureta Uriarte, Pedro. "La prohibición de competencia y la buena fe contractual”, en: Estudios de Derecho del Trabajo y de la Seguridad Social. Tomo I. Santiago, Chile: LegalPublishing, 2012, p. 85.

Ibid., p. 86

Sirvent Hernández, Nancy. El pacto de permanencia en la empresa. España, Valencia: Tirant lo Blanch, 2002, p. 38.

Ibid., p. 44.

Ibid.
} 
"Los funcionarios seleccionados para seguir cursos capacitación tendrán la obligación de asistir a éstos, desde el momento en que hayan sido seleccionados, y los resultados obtenidos deberán considerarse en sus calificaciones.

Lo anterior, implicará la obligación del funcionario de continuar desempeñándose en la institución respectiva o en otra de la Administración del Estado a lo menos el doble del tiempo de extensión del curso de capacitación.

El funcionario que no diere cumplimiento a lo dispuesto en el inciso precedente deberá reembolsar a la institución que corresponda todo gasto en que ésta hubiere incurrido con motivo de la capacitación. Mientras no efectuare este reembolso, la persona quedará inhabilitada para volver a ingresar a la Administración del Estado, debiendo la autoridad que corresponda informar este hecho a la Contraloría General de la República”.

En otros ordenamientos laborales, como el español, sí tiene reconocimiento expreso esta figura. El art. 21.4 del Estatuto de los Trabajadores dispone lo siguiente:

"Cuando el trabajador haya recibido una especialización profesional con cargo al empresario para poner en marcha proyectos determinados o realizar un trabajo específico, podrá pactarse entre ambos la permanencia en dicha empresa durante cierto tiempo. El acuerdo no será de duración superior a dos años y se formalizará siempre por escrito. Si el trabajador abandona el trabajo antes del plazo, el empresario tendrá derecho a una indemnización de daños y perjuicios".

De acuerdo con el tenor de esta disposición se sostiene que el pacto de permanencia es un acuerdo negocial a través del cual el trabajador se compromete a permanecer en la empresa que le ha procurado cierto nivel de formación -más o menos cualificada-, durante un período de tiempo acotado, y cuya finalidad es la de garantizar a la empresa la amortización de, al menos, los gastos que para ella ha supuesto la inversión económica efectuada en la especialización del trabajador?

En razón de lo expuesto, es posible deducir los elementos fundamentales de esta clase de pactos, a saber: a) que el trabajador reciba una calificación profesional con cargo a la empresa; b) que el trabajador debe permanecer en la empresa un tiempo determinado; c) que si el trabajador abandona la empresa antes del plazo estipulado deben resarcir los perjuicios ocasionados al empleador.

Si recordamos los términos del convenio de permanencia objeto de la sentencia, vemos que cumple precisamente con las características antes mencionadas. En este caso, la carga que asumía la Universidad consistía en mantener las remuneraciones al profesor, mientras éste se perfeccionaba en el exterior, por ende, en un período donde no se encontraba prestando servicios. Por su parte, el trabajador se comprometía a una permanencia en la Universidad equivalente al tiempo en que llevó a cabo sus estudios de perfeccionamiento, más un año. Finalmente, en el supuesto que el profesor incumpliera el pacto, asumía el compromiso de restituir los desembolsos que se le habían efectuado durante dichos estudios.

Ibid., p. 24. 
Como se advierte, esta clase de pacto dificulta la libre renuncia del trabajador ${ }^{10}$. En tal sentido, me parece que pudiera verse afectada la garantía constitucional de la libertad de trabajo (núm. 16 art. 19), en particular la "libertad de elección del trabajo" que supone que nadie puede ser obligado a prestar un servicio determinado sin su consentimiento ${ }^{11}$. Obviamente, una manifestación clara de esta libertad es el derecho que tiene todo trabajador a renunciar a su empleo (núm. 2 art. 159 Código del Trabajo) por los motivos que estime pertinente, normalmente por el cambio a otro trabajo o por el inicio de una actividad por cuenta propia.

La sentencia en comento no se plantea el análisis de este asunto, que considero, como decíamos, es una de las cuestiones claves que suscita esta clase de pacto. Pienso que, en todo caso, las razones que se desarrollan en la sentencia para justificar la existencia de un pacto como el del caso ${ }^{12}$, de manera implícita vienen a dar ciertos criterios para fundamentar su validez de cara al derecho fundamental indicado.

A mi entender, un pacto como el de la sentencia en análisis, sin duda, afecta la libertad del trabajo del profesor, pero no de manera ilícita. Pues conforme a los términos pactados, la limitación al derecho fundamental no afecta su esencia o núcleo irreductible, y además resulta justificada en interés del propio trabajador. En efecto, en este supuesto cada una de las partes asumió una obligación destinada a procurarse un beneficio legítimo. Como señalaba la Corte Suprema, la Universidad decidió pagar las remuneraciones al profesor, durante su estadía en el exterior, aun cuando éste no le iba a prestar servicios, con miras a contar con personal docente de alta calificación. El profesor decidió, a su vez, comprometerse a permanecer un tiempo determinado como dependiente de la Universidad (por el mismo lapso en que realizó sus estudios más un año) con el objeto de seguir percibiendo sus remuneraciones en ese lapso.

Creo que no requiere mayor explicación el que se aprecie como un importante beneficio para un trabajador, el que pueda continuar recibiendo sus remuneraciones, a pesar de no prestar servicios a su empleador, mientras realiza estudios fuera o dentro de Chile. En tal sentido, me parece justo que el trabajador asuma como contrapartida la obligación de permanencia (por un tiempo razonable) en la empresa, con la consecuencia que en caso de incumplimiento deba restituir las cantidades que ha recibido durante su permiso remunerado. En este contexto, se ha sostenido que conforme al principio de buena fe parece esperable de un trabajador, que ha recibido especialización con cargo a la empresa, la permanencia en ella durante cierto tiempo: el suficiente para que, sin anular por completo su libertad profesional, pueda aquélla beneficiarse de la prestación de servicios cualificada ${ }^{13}$.

Quiero subrayar, eso sí, que la permanencia que se pacte debe ser por un tiempo acotado y prudente, y que debe guardar relación con el beneficio recibido por parte de la empresa. A su vez, no creo que por cualquier clase de capacitación que se reciba por parte de la empresa, surja la oportunidad para ésta de suscribir con el trabajador un pacto de esta clase. A este respecto, es necesario recordar que el art. 179 CT dispone que "la empresa es responsable de las actividades relacionadas con la capacitación ocupacional de sus trabajadores, entendiéndose por tal, el proceso destinado a promover, facilitar, fomentar y desarrollar las aptitudes, habilidades o grados de conocimientos de los

\footnotetext{
10 Irureta Uriarte, Pedro, op. cit. (n. 5), p. 85.

11 Bronfman Vargas, Alan; Martínez Estay, José Ignacio; Núñez Poblete, Manuel. Constitución Politica comentada. Santiago, Chile: AbeledoPerrot- Legal, 2012, p. 338.

12 Véase apartado 1.2.3

13 Sirvent Hernández, Nancy, op. cit. (n. 7), p. 109.
} 
trabajadores, (...) procurando la necesaria adaptación de los trabajadores a los procesos tecnológicos” $(\text { art. } 179 \mathrm{CdT})^{14}$.

En esta línea, me parece pertinente citar una sentencia del Tribunal Supremo español, la cual indica que la especialización profesional a cargo de la empresa que justifica el pacto de permanencia es "aquella formación singular cualificada, que suponga un coste especial extraordinario para la empresa, y que produzca al mismo tiempo un enriquecimiento del patrimonio o valor profesional del trabajador fácilmente identificable" 15 . Por tales consideraciones, estimo que el costo que asuma la empresa debe ser cierta relevancia en orden que amerite razonablemente la justificación de limitar el derecho a la libertad de trabajo, según antes se explicaba.

\subsection{Naturaleza jurídica del PaCto}

Recordemos que la Corte Suprema estima que el pacto de permanencia objeto de la sentencia tenía carácter civil, pues lo entendía ajeno a la relación laboral. Esto en razón que la obligación de retornar a su puesto de trabajo y desempeñarse en él por cierto período o, en su defecto, devolver las sumas pagadas por la Universidad durante el período correspondiente, no eran propias de un contrato de trabajo individual, en la medida en que ellas no se refieren a la prestación de servicios.

No concuerdo con este criterio de la Corte, ya que a mi entender el pacto en cuestión tenía naturaleza laboral. Prima facie, cabe tener en cuenta que éste fue suscrito por dos partes pertenecientes a una relación laboral y que éstas estipularon expresamente que él se consideraba un anexo integrante del contrato de trabajo que las vinculaba. Como se apuntó, del pacto en cuestión surgían obligaciones recíprocas para el empleador y el trabajador. Así la Universidad debía seguir pagando las remuneraciones al profesor mientras realizaba sus estudios en el exterior. Bueno, queda claro que, al menos, esta parte llevaba a cabo una obligación que eminentemente tenía carácter laboral, según se deduce de la propia definición de contrato de trabajo (cfr. art. 7 Código del Trabajo, en adelante "CT"), de su condición de estipulación esencial del mismo contrato (cfr. núm. 4 art. 10 CT) y de todas las disposiciones del Código del ramo que regulan esta materia (arts. 41 y ss. CT). Por su parte, el profesor asumía el compromiso de prestar sus servicios en la Universidad por un determinado tiempo. Es decir, se obligaba a permanecer en la misma institución para realizar la obligación principal de todo trabajador. De esta manera, no me parece acertado el criterio de la Corte, en orden a que esta obligación de permanencia no tiene relación con la prestación de servicios. Igualmente, es necesario precisar que no todas las estipulaciones de un contrato de trabajo se refieren en estricto rigor a las funciones que debe desarrollar un trabajador. Se puede dar como ejemplo las cláusulas de no competencia vigente el contrato (cfr. núm. 2 art. $160 \mathrm{CT}$ ) o post-contractual ${ }^{16} \mathrm{es}$, como también los pactos de confidencialidad ${ }^{17}$.

De acuerdo al art. 10 CT, el contrato de trabajo debe contener obligatoriamente una serie de estipulaciones, tales como la individualización de las partes, la determinación de la naturaleza de los servicios, el monto, forma y período de pago de la remuneración acordada, la duración y distribución de la jornada de trabajo, etc. Asimismo, esta disposición prescribe que las partes podrán acordar en el contrato otros "pactos". Evidentemente, dentro de esta clase de pactos se podría encontrar una cláu-

\footnotetext{
14 En este orden, el art. 183 bis CT sólo permite al empleador que ha proporcionado capacitación a un menor de 24 años de edad, con el consentimiento de éste, imputar el costo directo de ella a las indemnizaciones por término de contrato de trabajo que pudieren corresponderle, con un límite de 30 días de indemnización.

15 Sentencia del Tribunal Supremo español (Unificación de Doctrina) 21 de diciembre de 2000, cit. Del Rey Guanter, Salvador. Estatuto de los Trabajadores. Comentado y con Jurisprudencia. $2^{\circ}$ Edición. España, Madrid: La Ley, 2007, p. 435.

16 Véase Corte Suprema 27 de enero de 2011, Rol 5152-2009.

17 Véase Dictamen Dirección del Trabajo, Ord. N 4731/081, de 3 de noviembre de 2010.
} 
sula de permanencia, ya sea acordada a partir de la suscripción del contrato, o bien, con posterioridad a través de un anexo. Según se puede apreciar, esta cláusula tiene su fundamento en el marco de un contrato de trabajo. Y es que la empresa sigue pagando las remuneraciones al trabajador, mientras se encuentra realizando sus estudios de perfeccionamiento, aun cuando no presté sus servicios durante dicho período, con miras a que éste continúe siendo parte de dicho contrato por un tiempo determinado. Por tales motivos, consideramos que este tipo de estipulación tiene naturaleza laboral.

No considero que se modifique este criterio por el hecho que se estipule para el caso de incumplimiento del pacto por parte del trabajador (sea que renuncie al trabajo, sea que se ponga término al contrato porque lo haya incumplido gravemente -resuelto ante un tribunal-), que éste se comprometa a compensar económicamente a la empresa. Resulta ilustrativo, en esta línea, el ya citado art. 21.4 del Estatuto de los Trabajadores espańol que dispone expresamente que si "el trabajador abandona el trabajo antes del plazo, el empresario tendrá derecho a una indemnización de dańos y perjuicios". Conforme a esta norma, la doctrina espańola sostiene que las partes antes de acontecer el incumplimiento pueden pactar, bien el quantum indemnizatorio, bien los criterios que han de ser considerados para calcular el monto de la indemnización ${ }^{18}$. Ciertamente, esto fue lo que aconteció en el caso en análisis, donde el profesor asumía la obligación de restituir las sumas que había recibido mientras se encontraba en el extranjero realizando sus estudios, y como se ha dicho no prestaba sus servicios.

Con todo, creo que a la hora de valorar el monto de la indemnización, se debería tener en cuenta si el trabajador ha cumplido parte de la permanencia pactada. En orden a que sí ha prestado sus servicios en una fracción de dicho de período, la indemnización tendría que ser de una suma inferior en comparación con quien no lo ha hecho. Así en el caso analizado, me parece que la indemnización debiera haberse reducido en una proporción razonable si el profesor había llevado a cabo sus funciones por un tiempo a su regreso del extranjero ${ }^{19}$.

\section{BIBLIOGRAFÍA}

Bronfman Vargas, Alan; Martínez Estay, José Ignacio; Núñez Poblete, Manuel. Constitución Política comentada. Santiago, Chile: AbeledoPerrot- Legal, 2012.

Del Rey Guanter, Salvador. Estatuto de los Trabajadores. Comentado y con Jurisprudencia. $2^{\circ}$ Edición. Espańa, Madrid: La Ley, 2007.

Irureta Uriarte, Pedro. "La prohibición de competencia y la buena fe contractual", en: Estudios de Derecho del Trabajo y de la Seguridad Social. Tomo I. Santiago, Chile: LegalPublishing, 2012.

Sirvent Hernández, Nancy. El pacto de permanencia en la empresa. España, Valencia: Tirant lo Blanch, 2002.

18 Sirvent Hernández, Nancy, op. cit. (n. 7), p. 260.

19 No encontré en la sentencia el antecedente de cuanto tiempo el trabajador prestó servicios una vez que regreso a su cargo. 